
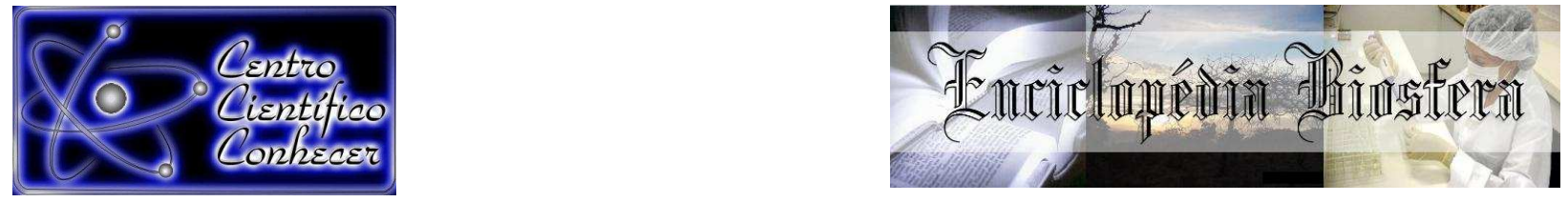

\title{
QUALIDADE FISIOLÓGICA DE SEMENTES DE SOJA EM FUNÇÃO DE DIFERENTES MANEJOS DE PERCEVEJOS COM INSETICIDAS
}

Pereclis Silva de Oliveira ; Bruna Zonta Brito1; Priscila Fernanda Simioni2; Oscar Mitsuo Yamashita ${ }^{3 ;}$ Ostenildo Ribeiro Campos ${ }^{3}$

(1) Graduado em Agronomia. Universidade do Estado de Mato Grosso - UNEMAT (pereclis_oliveira@hotmail.com) Alta Floresta - MT.

(2) Mestranda em Biodiversidade e Agroecossistemas Amazônicos. Universidade do Estado de Mato Grosso - UNEMAT (priscila-simioni@hotmail.com) Alta Floresta MT.

(3) Eng. Agrônomo. Doutor, Professor da UNEMAT - Departamento de Agronomia (campos@unemat.br) Alta Floresta-MT.

Recebido em: 08/09/2015 - Aprovado em: 14/11/2015 - Publicado em: 01/12/2015 DOI: http://dx.doi.org/10.18677/Enciclopedia_Biosfera_2015_217

\begin{abstract}
RESUMO
As pragas atacam a soja (Glycine max L.) durante todo o ciclo da cultura, principalmente os percevejos, que causam danos aos grãos desde o período de enchimento até a maturação causando perda na viabilidade. Sabendo que a qualidade de semente reduz com o aumento de percevejos, o presente trabalho teve o objetivo de avaliar diferentes populações desses pentatomídeos com vários métodos. O experimento foi composto por 5 lotes de sementes de soja provenientes de cultivos onde a variável foi o controle de percevejos, sendo (controle preventivo; 1 percevejo por pano de batida; 2 percevejos por pano de batida; 3 percevejos por pano de batida e 4 percevejos por pano de batida). As sementes foram submetidas a teste de teste de germinação, Teste de emergência a campo, Teste de condutividade elétrica, Teste de tetrazólio, Teste de envelhecimento acelerado. Acima de 3 percevejos por pano de batida provocam redução significativa no vigor das sementes.
\end{abstract}

PALAVRAS-CHAVE: controle, tetrazólio, Glycine max L. Piezodorus guildinii,

\section{PHYSIOLOGICAL QUALITY OF SOYBEAN SEEDS AS A FUNCTION OF DIFFERENT MANAGEMENTS OF BEDBUGS WITH INSECTICIDES}

\begin{abstract}
The pests attack the soybean (Glycine max L.) throughout the crop cycle, particularly bedbugs, causing damage to the grain filling period since until maturation causing loss of viability. Knowing that quality seed reduces with the increase of bed bugs, the present study aimed to evaluate the quality of these seeds in different populations pentatomids with various methods of force analysis. The experiment consisted of 5 batches of soybean seeds from crops where the variable was the control of bedbugs being (preventive control, 1 cloth bug by tapping, 2 cloth hit by bedbugs, 3 cloth hit by bedbugs and 4 bedbugs hit by cloth). The seeds were subjected to test germination
\end{abstract}


test, Test field emergence, electrical conductivity test, tetrazolium test, accelerated aging test. Over 3 bugs per cloth beat cause significant reduction in seed vigor.

KEYWORDS: Piezodorus guildinii, control, tetrazolium, Glycine max L.

\section{INTRODUÇÃO}

Por ser considerada de grande importância econômica no cenário agrícola brasileiro, a semente de soja (Glycine max L.) é avaliada por diversos testes que permitem verificar seu potencial fisiológico. Os testes de qualidade de semente têm finalidade de avaliar a viabilidade, vigor de sementes, potencial germinativo, além de apontar possíveis causadores de danos nas sementes, como danos mecânicos, ataque de percevejos, entre outros como a relacionadas à umidade relativa a campo, choques mecânicos, deteriorização por micro-organismos (CORREA-FERREIRA et al., 2009).

As pragas que atacam a soja ocorrem durante todo o ciclo da cultura, sendo assim indiscutível a importância do manejo integrado de pragas (MIP), onde serão tomadas decisões quanto ao controle dos insetos causadores de danos, considerando sempre um nível em que o custo com inseticidas e aplicações se equivale ao rendimento por área (CARVALHO \& BARCELLOS, 2012).

São constituídas como principais pragas no cultivo da soja, as lagartas desfolhadoras (a lagarta da soja: Anticarsia gemmatalis e as lagartas falsamedideira, principalmente a Pseudoplusia includens) e os percevejos (Nezara viridula, Piezodorus guildinii e Euschistus heros). Os percevejos aparecem a partir da floração, causando os maiores danos entre os estádios de desenvolvimento das vagens e final do enchimento dos grãos. Seus ataques podem causar considerável redução no rendimento e na qualidade da semente. $O$ ataque de percevejos na cultura da soja expressa redução na produtividade, pelo aborto de vagens e/ou grãos, menor tamanho e peso de semente; diminuição do potencial germinativo e vigor da semente; a anomalia conhecida como soja louca, quando ocorre retenção foliar, fazendo com que a planta permaneça verde enquanto as sementes estejam maduras (HOFFMANN CAMPO et al., 2000).

Os percevejos colonizam a soja no final do período vegetativo (V6-V8), época em que estes saem da quiescência ou plantas hospedeiras e migram para a soja. Com isso, a população tende a crescer provocando os danos significativos na produtividade no período de enchimento dos grãos (R5. 1-R6). Os danos causados pelos percevejos são em maioria causadas pela forma jovem, entre os terceiro e quinto instares, provocando redução no percentual germinativo das sementes (CORREA-FERREIRA et al., 2009).

$\mathrm{Na}$ busca para avaliar o potencial de germinativo, testes que determinam o vigor de sementes tem adquirido espaço, comprovando através de métodos que avaliam indiretamente o potencial que certo lote de semente possui para o estabelecimento de plântulas proveniente de uma boa germinação (MARCOS FILHO et al., 2001). Os testes que visam à determinação do vigor de sementes são diversos, sendo que de modo geral, tendem aperfeiçoar a avaliação para apresentar um resultado rápido e confiável (MARCOS FILHO, 1999).

A metodologia desses testes varia de acordo com o foco de interesse das diferentes variáveis que expressam informações seguras sobre o vigor das sementes, tais como a capacidade de germinação uniforme em reduzido espaço temporal, a condutividade elétrica das sementes e o nível de coloração das 
sementes tratadas com sal de tetrazólio que sofreram ataque de insetos (COPELAND \& McDONALD, 2001).

O teste de germinação é um dos métodos mais utilizados para classificar a qualidade germinativa de lotes de sementes, consideravelmente útil, porém é demorado e não informa sobre o potencial de desempenho considerando seu vigor, longevidade e emergência de plântulas a campo (DELOUCHE, 2002). Com isso, torna-se de fundamental importância testes complementares, avaliando a qualidade de modo mais eficiente permitindo assim maior diferenciação entre lotes. Os testes mais recomendados para determinação do vigor de lotes de sementes de soja, segundo VIEIRA et al., (2003) são: envelhecimento acelerado, tetrazólio, condutividade elétrica e crescimento de plântulas.

Esses métodos, usados para diagnosticar o vigor das sementes, têm sido responsáveis pelo bom andamento da produção atualmente, pois auxiliam na escolha de material de qualidade. Dentre eles, se destaca o teste tetrazólio que, aplicado no decorrer da produção, aponta os agentes causadores de perdas de qualidade, sendo possível assim, adotar manejos, métodos ou ações corretivas para que venha amenizar a queda de qualidade dos grãos (CARVALHO \& NOVEMBRE, 2012).

Sabendo que a produtividade tende a diminuir juntamente com a qualidade de sementes quando submetidas a níveis crescentes de infestação de percevejos, o presente trabalho avaliou a viabilidade sementes de soja com variados níveis de controle de percevejos.

\section{MATERIAL E MÉTODOS}

Os métodos de avaliação aplicados para a determinação do vigor das sementes do presente trabalho foram desenvolvidos no Laboratório de Sementes do Centro de Tecnologia da Amazônia Meridional (CETAM) da Universidade do Estado de Mato Grosso (UNEMAT) Campus II de Alta Floresta.

As sementes utilizadas foram obtidas de um experimento anterior com cinco tratamentos e quatro repetições, sendo os tratamentos: T1- Controle preventivo; T2 - 1 percevejo por pano de batida; T3 -2 percevejos por pano de batida; T4 - 3 percevejos por pano de batida e T5 - 4 percevejos por pano de batida. As amostragens foram realizadas semanalmente para cada tratamento, a partir do inicio do desenvolvimento das vagens. Quando o nível de controle de percevejo alcançava o seu limite, as aplicações de inseticidas (tiametoxam + lambda-cialotrina) foram efetuadas.

Após a maturidade fisiológica, as sementes foram colhidas e colocadas para secar a sombra. A umidade das sementes foi determinada pelo método direto (BRASIL, 2009), através de secagem a $105^{\circ} \mathrm{C}$ em estufa de circulação forçada de ar por 24 horas.

As sementes de soja foram submetidas aos seguintes testes:

Teste de padrão de germinação: realizado segundo as Regras para Análise de Sementes - RAS (BRASIL, 2009). Foram semeadas 200 sementes por tratamento, divididas em quatro repetições de 50 sementes, em rolo de papel toalha germitest umedecido com água. As sementes foram levadas ao germinador à temperatura de $25^{\circ} \mathrm{C}$ por oito dias, quando foi realizada a avaliação. Os resultados foram expressos em porcentagem de sementes germináveis e não germináveis.

Teste de condutividade elétrica: quatro subamostras de 50 sementes foram separadas, pesadas e colocadas em copinhos de plástico, sendo 
acrescentados $75 \mathrm{~mL}$ de água deionizada e mantidos por 24 horas a uma temperatura de ${ }^{25^{\circ} \mathrm{C}}$ (VIEIRA, 1994). Após este perío do, com auxílio de um condutivímetro (modelo CD 850 Instrutherm ${ }^{\circledR}$ ), foi determinada a condutividade elétrica da solução de cada amostra. Os resultados foram divididos pelo peso da amostra, assim a condutividade foi expressa em $\mu \mathrm{Sm}^{-1} \mathrm{~g}^{-1}$ de semente.

Teste de envelhecimento acelerado: foram usadas caixas gerbox (11 $\mathrm{cm} \times 11 \mathrm{~cm} \times 3 \mathrm{~cm}$ ), para cada tratamento. Os tratamentos divididos em 4 subamostras de 50 sementes foram dispostas em camada única sobre tela de arame em caixas de gerbox, contendo $40 \mathrm{~mL}$ de água destilada (100\% UR), mantida a $42^{\circ} \mathrm{C}$, por 48 horas (MARCOS FILHO, 1999). Após es se período, procedeu-se o teste padrão de germinação como descrito anteriormente, para avaliação do percentual de sementes viáveis, após 5 dias.

Teste de tetrazólio: foram utilizadas quatro subamostra de 50 sementes de cada tratamento, conforme metodologia descrita por (BHERING et al., 1999). As sementes foram pré-acondicionadas entre duas folhas de papel germitest umedecidas com 2,5 vezes o seu peso com água destilada, na câmara Mangelsdorff regulado à temperatura de $25{ }^{\circ} \mathrm{C}$, durante 16 horas. Após o condicionamento, as sementes foram colocadas na solução de 2,3,5-trifenil-cloreto-de-tetrazólio a 0,075\% e armazenada à temperatura de $40{ }^{\circ} \mathrm{C}$ por 3 horas, pa ra o desenvolvimento da coloração. Posteriormente, as sementes foram seccionadas longitudinalmente e agrupadas em sementes germináveis normais, anormais e sementes não germináveis.

Emergência de plântulas: em bandejas contendo como substrato areia fina lavada, as repetições de cada tratamento foram dispostas formando uma linha com 50 sementes para cada repetição. Umedecida com água e reumedecida quando necessário, mantidas em condições de laboratório, com máxima e mínima de temperatura $31^{\circ} \mathrm{C}-24^{\circ} \mathrm{C}$, e umidade relativa $25 \%-62 \%$, respectivamente. No $8^{\circ}$ dia, foi determinada a percentagem média de emergência de plântulas para cada repetição. As plântulas foram levadas a estufa a $65^{\circ} \mathrm{C}$ por 48 horas, onde se obteve a média de massa seca por repetição.

Determinação de umidade de semente: foram coletadas duas repetições de cada tratamento, aproximadamente $5 \mathrm{~g}$. Foram utilizadas placas de petri que foram levadas a estufa sob a temperatura de $105^{\circ} \mathrm{C}$ por 24 horas, passado esse período a massa de cada repetição foi novamente determinada, sendo a umidade da semente a diferença entre o peso inicial e final.

Os dados foram analisados com auxílio do software SISVAR, utilizandose o delineamento inteiramente casualizado, com quatro repetições sendo análise de variância e as médias comparadas pelo teste de Tukey a $5 \%$ de probabilidade (FERREIRA, 2008).

\section{RESULTADOS E DISCUSSÃO}

A umidade das sementes dos diferentes tratamentos apresentou média de $12,8 \%$, variando entre 11,2 e $13,5 \%$, o que indica uniformidade dos lotes em relação a esse fator. Essa média está dentro dos padrões recomendados para armazenamento e análise fisiológica das sementes de soja, não havendo comprometimento nos resultados. A umidade pode afetar o comportamento das sementes durante testes de vigor. Segundo MARCOS FILHO (1999), para o teste de envelhecimento acelerado, sementes úmidas são muito mais sensíveis à condições 
provocadas por este tipo de teste. Entretanto, uma variação de umidade entre 1 e $2 \%$ no conjunto de amostras não comprometem os resultados obtidos.

O resumo da analise de variância realizado para os testes de germinação e de vigor estão apresentados na Tabela 1.

TABELA 1. Quadrado médio dos valores de germinação de sementes de soja produzidas em função de diferentes tratamentos para controle de ataque de percevejos. \%G - teste padrão de germinação; TTZ - teste de tetrazólio; C - condutividade elétrica; \%E - emergência a campo; EA envelhecimento acelerado; MS - massa seca de plântula. Alta Floresta MT, 2012.

\begin{tabular}{lcccccc}
\hline F.V. & $\% \mathrm{G}$ & $\mathrm{TTZ}$ & $\mathrm{C}$ & $\% \mathrm{E}$ & $\mathrm{EA}$ & $\mathrm{MS}$ \\
\hline Tratamento & $1,6921^{*}$ & $3,6283^{*}$ & $0,0013 \mathrm{~ns}$ & $0,5008 \mathrm{~ns}$ & $8,1521^{*}$ & $0,0414 \mathrm{~ns}$ \\
Resíduo & 0,3688 & 0,2505 & 0,0042 & 1,0372 & 0,8312 & 0,1005 \\
\hline C.V. (\%) & 6,77 & 6,50 & 4,99 & 14,56 & 13,58 & 15,78 \\
\hline *-significativo a 5\% de probabilidade & \multicolumn{5}{c}{ ns - não-signficativo } \\
Valores transformados em (raiz $(\mathrm{x}+0,5))$ & \multicolumn{5}{c}{}
\end{tabular}

Para a germinação de sementes, observa-se menores percentuais quando o controle de ataque de percevejos foi mantido com 3 indivíduos, não diferenciando porém dos tratamentos com 2 e 4 percevejos (Tabela 2). Esses resultados permitiram inferir que a presença de até um indivíduo não prejudica a germinação das sementes de soja, confirmando a recomendação técnica para a cultura de até 2 percevejos por pano de batida (GAZZONI et al., 1981). Entretanto discordam dos obtidos por GAZZONI (1998) e VILLAS-BOAS et al. (1990) que relatam não haver diferença na qualidade das sementes de soja se a lavoura for atacada por uma população de até 4 percevejos por pano de batida.

TABELA 2. Germinação de sementes de soja produzidas em função de diferentes tratamentos para controle de ataque de percevejos. Alta Floresta - MT, 2012.

\begin{tabular}{lc}
\hline Tratamento & \% germinação de sementes \\
\hline Controle preventivo & $90,5 \mathrm{a}$ \\
1 percevejo & $88,0 \mathrm{a}$ \\
2 percevejos & $81,0 \mathrm{ab}$ \\
3 percevejos & $62,5 \mathrm{~b}$ \\
4 percevejos & $81,5 \mathrm{ab}$ \\
\hline C.V.(\%) & 6,77 \\
\hline
\end{tabular}

Médias seguidas de mesma letra não diferem entre si pelo teste de Tukey a $5 \%$ de probabilidade.

No teste de tetrazólio, observou-se diferença significativa das médias apenas em sementes vigorosas (Tabela 3 ). Esses resultados demonstraram claramente a redução no percentual de sementes vigorosas à medida que o número de percevejos por pano de batida era aumentado, chegando a ser metade desse percentual quando a população era de 4 insetos. $O$ impacto da alimentação dos percevejos pode causar perdas significativas no rendimento, na qualidade e no 
potencial germinativo da soja (SANTOS 2003; CORRÊA-FERREIRA 2005), como observado na germinação das sementes de soja.

$O$ resultado verificado está condizente, pois lotes com menor percentual de sementes viáveis naturalmente tem que apresentar maiores percentuais de sementes médias ou ruins. Quando se trata de qualidade média, significa que, em um mesmo lote, são reunidas sementes com danos de percevejos que, apesar de serem de pequena intensidade, ainda são constatados, entretanto, não provocam deformações intensas na semente. Esta característica é complementar às de sementes tidas como boas, pois esta situação não provoca efeito negativo direto no vigor e na viabilidade da semente. Vale ressaltar que, nesta condição, haverá tendência de aumento no número de picadas, porém de reduzida intensidade. Assim, uma parcela das sementes de qualidade boa pode ser agrupada para qualidade média, embora o genótipo apresente uma provável característica de melhor qualidade de semente (GAZZONI, 1998).

TABELA 3. Teste de tetrazólio em sementes de soja produzidas em função de diferentes tratamentos para controle de ataque de percevejos. Alta Floresta-MT, 2012.

\begin{tabular}{lccl}
\hline \multirow{2}{*}{ Tratamento } & \multicolumn{3}{c}{ Teste de tetrazólio } \\
\cline { 2 - 4 } & Vigorosas & Não-vigorosas & Anormais \\
\hline Controle preventivo & $82,5 \mathrm{a}$ & $12,5 \mathrm{a}$ & $20,0 \mathrm{a}$ \\
1 percevejo & $59,5 \mathrm{bc}$ & $25,5 \mathrm{a}$ & $15,0 \mathrm{a}$ \\
2 percevejos & $64,0 \mathrm{ab}$ & $19,5 \mathrm{a}$ & $16,5 \mathrm{a}$ \\
3 percevejos & $44,5 \mathrm{c}$ & $18,5 \mathrm{a}$ & $37,0 \mathrm{a}$ \\
4 percevejos & $48,5 \mathrm{bc}$ & $24,5 \mathrm{a}$ & $27,5 \mathrm{a}$ \\
\hline C.V.(\%) & 6,50 & 20,13 & 35,30 \\
\hline
\end{tabular}

Médias seguidas de mesma letra não diferem entre si pelo teste de Tukey a $5 \%$ de probabilidade.

Para o envelhecimento acelerado, observa-se uma tendência similar aos resultados obtidos nos demais testes de vigor, em que à medida que o número de percevejos aumenta, a capacidade germinativa das sementes é significativamente reduzida (Tabela 4 ).

TABELA 4. Condutividade elétrica (C), emergência a campo (\%E), massa seca de plântulas (MS) e envelhecimento acelerado (EA) de sementes de soja produzidas em função de diferentes tratamentos para controle de ataque de percevejos. Alta Floresta-MT, 2012.

Tratamento Testes de vigor

\begin{tabular}{lllll} 
& C & $\% \mathrm{E}$ & MS & $\mathrm{EA}$ \\
\hline Controle preventivo & $1,235075 \mathrm{a}$ & $48,5 \mathrm{a}$ & $3,4375 \mathrm{a}$ & $73,5 \mathrm{a}$ \\
1 percevejo & $1,189977 \mathrm{a}$ & $55,0 \mathrm{a}$ & $3,8050 \mathrm{a}$ & $51,0 \mathrm{ab}$ \\
2 percevejos & $1,263725 \mathrm{a}$ & $52,5 \mathrm{a}$ & $4,2550 \mathrm{a}$ & $51,0 \mathrm{ab}$ \\
3 percevejos & $1,224058 \mathrm{a}$ & $46,0 \mathrm{a}$ & $3,2925 \mathrm{a}$ & $33,5 \mathrm{bc}$ \\
4 percevejos & $1,140567 \mathrm{a}$ & $44,5 \mathrm{a}$ & $3,3150 \mathrm{a}$ & $25,0 \mathrm{c}$ \\
\hline C.V.(\%) & 4,99 & 14,56 & 15,78 & 13,58 \\
\hline
\end{tabular}

Médias seguidas de mesma letra não diferem entre si pelo teste de Tukey a $5 \%$ de probabilidade. 
Este teste de vigor demonstra que o dano causado por espécies de percevejo como Piezodorus guildinii e Euschistus heros, os principais causadores de danos em sementes de soja, provocam redução na capacidade germinativa das sementes. Trabalhos desenvolvidos por CORRÊA-FERREIRA \& AZEVEDO (2002), SANTOS (2003) e CORRÊA-FERREIRA (2005) confirmam os danos qualitativos e quantitativos de $P$. guildinii às sementes de soja, que verificaram a inviabilidade das sementes em plantas infestadas com até 4 percevejos por metro quadrado.

O estabelecimento de um estande com uniformidade e rapidez na emergência determina seu sucesso posterior, podendo assim alcançar desenvolvimento superior tanto na fase vegetativa como na reprodutiva. De acordo com KOLCHINSKI et al., (2006), o crescimento de inicial de plantas de soja onde foram usadas das sementes de alto vigor apresentaram maior área foliar e produção de matéria seca.

\section{CONCLUSÃO}

Acima de três percevejos por pano de batida provocam redução significativa no vigor das sementes de soja produzidas sob essa infestação.

\section{REFERÊNCIAS}

BHERING, M. C.; SILVA, R. F.; ALVARENGA, E. M.; DIAS, D. C. F. S. Metodologia do teste de tetrazólio em sementes de feijão. In: KRZYZANOWSKI, F. C.; VIEIRA, R. D; FRANÇA NETO, J.B. (Ed.). Vigor de sementes: conceitos e testes. Londrina: ABRATES, cap. 8, p. 1-10.1999.

BRASIL. Ministério da Agricultura e da Reforma Agrária. Secretaria Nacional de Defesa Agropecuária. Regras para análise de sementes. Brasília, 2009. 365 p.

CARVALHO, N.L.; BARCELLOS, A.L. Adoção do manejo integrado de pragas baseado na percepção e educação ambiental. Revista Eletrônica em Gestão, Educação e Tecnologia Ambiental, v.5, n.5, p.749-766, 2012.

CARVALHO, T. C.; NOVEMBRE, A. D. L. C. Comparação de métodos para avaliação de injúrias mecânicas em sementes de duas cultivares de soja. Revista Brasileira Ciências Agrárias, v. 7, n. 3, p. 372-379, 2012.

COPELAND, L. O.; McDONALD, M. B. Principles of seed science and technology, Kluwer Massachusets: Academic Publishers, 4.ed. p.165-192, 2001.

CORRÊA-FERREIRA, B. S. Suscetibilidade da soja a percevejos na fase anterior ao desenvolvimento das vagens. Pesquisa Agropecuária Brasileira, v.40, n.11, p.1067-1072, 2005.

CORRÊA-FERREIRA, B. S.; AZEVEDO, J. Soybean seed damage by different species of stink bugs. Agriculture and Forest Entomology, v.4, p.145-150, 2002.

CORREA-FERREIRA, B. S.; KRZYZANOWSKI, F. C.; MINAMI, C.A. Percevejo e a qualidade da semente de soja - série sementes. Circular Técnica EMBRAPA. Londrina - PR. Abril, 2009. 15p.. 
DELOUCHE, J. Germinação, deterioração e vigor da semente. Seed News, n.6, p.24-31, 2002.

FERREIRA, D. F. SISVAR: um programa para análises e ensino de estatística. Revista Symposium, Lavras, v. 6, n.1, p. 36-41, 2008.

GAZZONI, D. L. Efeito de populações de percevejos na produtividade, qualidade da semente e características agronômicas da soja. Pesquisa Agropecuária Brasileira, v. 33, n. 8, p. 1229-1237, 1998.

GAZZONI, D. L.; OLIVEiRA, E. B.; CORSO, I. C.; FERREIRA, B. S. C.; VILLAS BOAS, G. L.; MOSCARDI, F.; PANIZZI, A. R. Manejo de pragas da soja. Londrina: EMBRAPA-CNPSo, 1981. 44p. (EMBRAPA-CNPSo. Circular Técnica, 5).

HOFFMANN-CAMPO, C. B.; MOSCARDI, F.; CORRÊA-FERREIRA, B. S.; OLIVEIRA, L. J.; SOSA-GÓMEZ, D. R.; PANIZZI, A. R.; CORSO, I. C.; GAZZONI, D. L.; OLIVEIRA, E. B. Pragas da soja no Brasil e seu manejo integrado. Circular Técnica EMBRAPA - CNPSo, n.30, p.1-70, 2000.

KOLCHINSKI, E. M.; SCHUCH, L. O. B.; PESKE, S. T. Crescimento inicial de soja em função do vigor das sementes. Revista Brasileira de Agrociência, v. 12, n. 2, p. 163-166, 2006.

MARCOS FILHO, J. Testes de vigor: Importância e utilização. In: KRZYZANOWSKI, F. C.; VIEIRA, R. D; FRANÇA NETO, J.B. (Ed.). Vigor de sementes: conceitos e testes. Londrina: ABRATES, Cap. 1, p. 1-21.1999.

MARCOS FILHO, J.; NOVEMBRE, A. D. C.; CHAMMA, H. M. C. P. Testes de envelhecimento acelerado e de deterioração controlada para avaliação do vigor de sementes de soja. Scientia Agricola, v. 58, n. 2, p.421-426, 2001.

SANTOS, C. H. Suscetibilidade da soja, Glycine max (L.) Merr. aos danos causados por Nezara viridula (L.), Euschistus heros (Fabr.) e Piezodorus guildinii (West.) (Heteroptera: Pentatomidae) e Neomegalotomus parvus West. (Heteroptera: Alydidae). 2003. 91f. Tese (Doutorado em Agronomia) - Universidade Federal do Paraná, Curitiba.

VIEIRA, R. D. Teste de Condutividade elétrica. In: VIEIRA, R. D.; CARVALHO, N. M. Testes de vigor em sementes. Jaboticabal: FUNEP, p.103-134.1994.

VIEIRA, R. D.; BITTENCOURT, S. R. M.; PANOBIANCO, M. Seed vigour - an important component of seed quality in Brazil. ISTA - Seed Testing International, n. 126, p. 21-22, 2003.

VILLAS BÔAS, G. L.; GAZZONI, D. L.; OLIVEIRA, M. C. N.; COSTA, N. P.; ROESSING, A. C.; HENNING, A. A. Efeito de diferentes populações de percevejos sobre 0 rendimento e seus componentes, características agronômicas e qualidade de semente de soja. Londrina: EMBRAPA-CNPSo, 1990. 43p. (EMBRAPA-CNPSo. Boletim de Pesquisa, 1). 